\title{
INFLUENCE OF SERVICE FACTORS IN THE MODEL OF PUBLIC TRANSPORT MODE: A BANJARMASIN - BANJARBARU ROUTE CASE STUDY
}

\author{
Iphan F. Radam ${ }^{1}$, Agus T. Mulyono' ${ }^{2}$ Bagus H. Setiadji ${ }^{3}$ \\ ${ }^{1}$ Study Program of Civil Engineering, Lambung Mangkurat University, Banjarmasin, Indonesia \\ ${ }^{2}$ Department of Civil Engineering, Gadjah Mada University, Yogyakarta, Indonesia \\ ${ }^{3}$ Department of Civil Engineering, Diponegoro University, Semarang, Indonesia
}

Received 26 August 2014; accepted 27 April 2015

\begin{abstract}
This research is aimed to examine the extent to which the service factors will affect the probability of people choice on public transports offered. The service factors are essential since the habits in the planning of new public transport at developing cities tend to prioritizes "travel time" and "travel cost" only. Consequently, there will be more than a small number of new public transports that will meet the same fate as the previous ones, i.e. unable to attract the users' interest. The research is focused on Banjarmasin City and Banjarbaru City which are two administrative cities with high development level and are large generation/attraction zones in South Borneo. The tendency of the use of private vehicles remains high with one of the reasons is the level of transportation services which are still low. Therefore, the planning of new alternative transports (bus) is required, in addition to the existing Paratransit transportation (mikrolet/Indonesian minibus). To obtain a utility and probability model of the of travelers (users) in selecting the public transport modes between the existing transports and new bus alternative transports, the Logit method approach was used and the data were collected by using Stated Preference technique. From the result of this research, the model of mode choice is obtained by including service factors showing the improvement of goodness of fit model, and is compared by those without including service factors. The average of service effect on the increase in the choice probability of the services is $22 \%$, both in the sensitivity of the travel time and travel costs.
\end{abstract}

Keywords: mode choice, stated preference, service factors.

\section{Introduction}

New public transport planning should at least observe characteristics of the trip maker, the characteristics of the journey, and characteristics of the transport facility (Ortuzar and Willumsen, 1994). In a homogeneous movement condition, the characteristics of the transport facilities become a crucial thing. However, frequently, the policy makers tend to notice more on the characteristics of the transport facilities from the quantitative factors only (travel time and travel cost), which in fact, there are other factors, i.e. quantitative factors that can affect the choice, such as the choice of the services provided. This issue is frequently encountered in developing cities,

\footnotetext{
${ }^{1}$ Corresponding author: ifradam@yahoo.com
} 
such as in the focus areas of the study, i.e. Banjarmasin and Banjarbaru. These cities are administration cities of which the general working movement is the biggest in South Borneo - Indonesia (an average of 2,000 passengers/day using public transports). These cities are located $\pm 40 \mathrm{~km}$ away from each other and paratransit transport type serves here (minibus/mikrolet). The lack of other alternative public transports results in the negligence of service factors, while the improvement of operational systems cannot run well. The effects from these may lead the users switch to the use of private vehicles. Therefore, by viewing the needs for large public transports as well as by referring to the "unsuccessful" new public transport planning which solely relies on travel time and travel cost, a study is required to consider the service factors.

The service improvement for public transport users has become a requirement, especially in a competitive system. The services, whether in the form of passengers' comfort while using the transport, the scheduled departure time (punctuality), the guarantee of safety and security as well as the ease in accessing the transport is highly influential in the people choice behavior in choice models (Hensher et al., 2005; Radam, 2010), and also the frequency of service appear to affect mode choice (Rigas, 2009). Reviewed in terms of vehicle facilities, dell'Olio et al. (2011) suggests that the affecting service factors are maintained cleanliness, modest drivers (safety perception), and comfortable vehicle condition (related to cool temperature). The services may also come in form of the distance between public transport facilities and the destination (distance and time efficiency) for the sake of comforts and the assurance of security (Eck et al., 2005). In addition, the time spent in the vehicles, the condition of the waiting rooms and the transports, the ease to move, and information on departure become the matters that should be brought into attention (Paulley et al., 2006). More specifically, the information on departure should contain time and frequency (Grdzelishvili and Sathre, 2011). Based on passengers' perception in Banjarmasin, Radam et al. (2014) suggests that the service quality as the major priority for improvement are arrival punctuality in destination cities, security and safety of luggage and passengers guarantee, the employees' friendliness in giving service, passengers' comfort on the vehicles. In addition, the performance that should be improved (low priority) is the attributes of the availability of complete supporting facilities, and guarantee to problem solving.

The service factors are what became the basis of this research to obtain the extent to which it would affect the travelling behavior in the determination of mode choice desired; between the old transport (mikrolet) and alternative bus transports, in addition to the effect of changes in attribute values of time and travel factors, and the extent to which the use of the service factors affecting the choice model formed.

\section{Methodology}

The investigation flow in this research (Fig. 1) was to identify the variables that would be investigated first, i.e. by comparing bus and mikrolet by considering the changes in the attributes of cost, travel time, and service factors from Banjarmasin to Banjarbaru and vice versa. The passengers who became the objects of the research were the usual captive passengers using the public transports. Once sorted, the data collection was then performed by 
using Stated Preference technique in the field, by using proportional simple random sampling, i.e. the sampling providing the equal opportunity for all members of the population with the population target set beforehand. The data obtained were then analyzed by using Logit Method to obtain the model of mode choice.

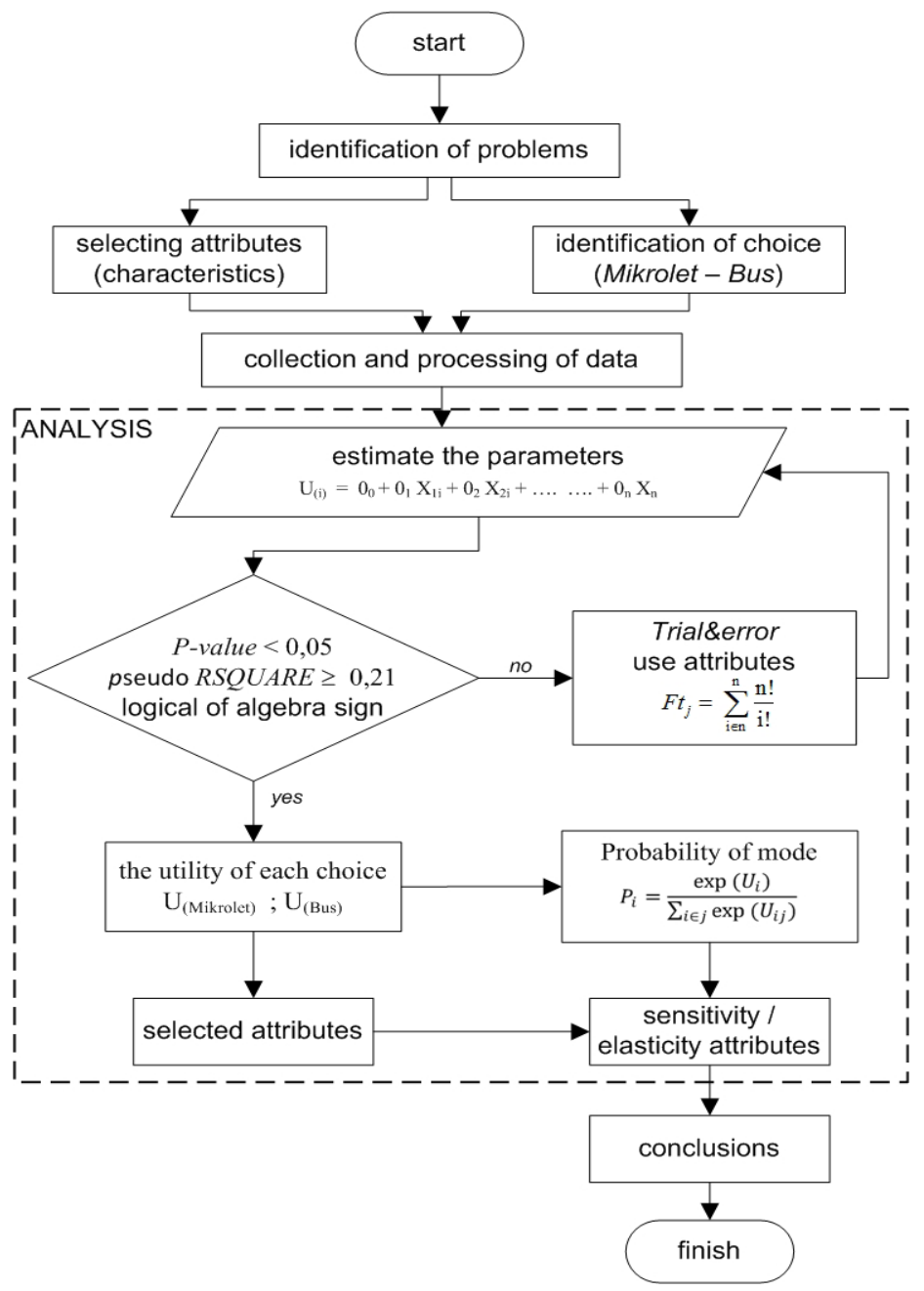

Fig. 1.

Research Flowchart

\subsection{Mode Choice Utility}

The hypothesis underlying discrete choice models is that when faced with a choice situation, especially individual choice on each alternative offered is commonly expressed by the measure of attractiveness or utility (Sheffi, 1992). The utility for the trip maker offered by particular alternative infrastructures is the measure becoming the assessment 
parameter for the choice by the trip maker. The function of this utility can be made by using field observations on the trip maker in terms of their behavior in selecting the mode of travelling routes that they will have.

The utility is commonly defined as a linear combination of several variables. The elaboration of the equation form utility by Ortuzar and Willumsen (1994) can be simplified such as Eq. (1):

$U j=\theta_{0}+\theta_{1} X_{1 j}+\theta_{2} X_{2 j}+\ldots .+\theta_{n} X_{n j}$

Where $U_{j}$ is the mode choice utility $j, X_{1} \ldots$ $X_{n}$ is an attribute of each choice, and $a_{0} \ldots a_{n}$ shows the constant value/ coefficient model.

\subsection{Stated Preference}

Stated preference (SP) technique is a choice method using respondents' individual statements about their choices in a set of options to estimate the function utility (Kroes and Sheldom, 1988). In general, the analysis used in the research using SP technique is Discrete Choice Model, which is a probabilistic model where the value of each respondent's choice is related to other choices within a set of alternatives offered. The general form of this model is the model with Logit function. If being applied to the two alternative modes, it will be referred as Binomial Logit function. The equation form simplification of the binomial Logit (Ben-Akiva and Lerman, 1985; Ortuzar and Willumsen, 1994) can be written as Eq. (2):

$P_{1}=\frac{\exp \left(U_{1}\right)}{\exp \left(U_{1}\right)+\exp \left(U_{2}\right)}$

Where $P_{1}=$ the probability of mode choice $1, U_{1}=$ the users alternative utility mode 1 , and $U_{2}=$ users alternative utility mode 2 .

\subsection{Measures of Goodness of Fit Model}

In terms of consistency and the statistical properties, the value of the coefficient of determination $\left(\mathrm{R}^{2}\right)$ yielded can explain the goodness of fit model measure. The value of coefficient of determination of this Logit model is called $\rho s e u d o-\mathrm{R}^{2}$ (Domencich and McFadden, 1975; Hensher et al., 2005; Hoetker, 2007). The model is said to have a relatively good fit if the $\rho s e u d o-\mathrm{R}^{2}$ condition is greater than 0.2 (Clark and Hosking, 1986). On the other hand, Hensher et al. (2005) provides a higher limitation for $\rho s e u d o-\mathrm{R}^{2}$ value, i.e. more than 0.3 . By combining the OLS correlation scale (Guildford, 1956) and Domencich and McFadden's Chart, the interpretation of the $\rho s e u d o-\mathrm{R}^{2}$ value based on coefficient of correlation on the model can be explained as shown in Table 1.

Table 1

Interpretation of $\rho s e u d o-R 2$ Based on Correlation Coefficient

\begin{tabular}{|l|l|l|l|}
\hline pseudo R2 value & R2 value & $\begin{array}{l}\text { Absolute value of } \\
\text { the correlation } \\
\text { coefficients }(|\mathbf{r}|)\end{array}$ & Interpretation \\
\hline$<0.014$ & $<0.04$ & $0.00-0.199$ & Slight correlation; almost negligible relationship \\
0.014 & 0.04 & $0.20-0.399$ & Low correlation; definite but small relationship \\
0.050 & 0.16 & $0.40-0.699$ & Moderate correlation; substantial relationship \\
0.210 & 0.49 & $0.70-0.899$ & High correlation; marked relationship \\
0.403 & 0.81 & $0.90-1.000$ & Very high correlation; very dependable relationship \\
\hline
\end{tabular}


Based on Table 1, pseudo- $\mathrm{R}^{2}$ value should be $\geq 0.21$ to show a significant relation with a high degree of correlation in the model obtained. Besides pseudo- $\mathrm{R}^{2}$ value, what should be noted in assessing the model accuracy is the extent to which the effects of the independent variables in explaining the variation in dependent variables individually. Generally, the P-value used is approaching $0(\alpha<0.05)$ to show that the attributes (independent variables) reviewed are valid for use. The algebraic sign of the attributes which is inversely proportional to the dependent variable is (-) and if directly proportional, it should be $(+)$, therefore, the logical criterion is fulfilled (Karno et al., 2004; Radam, 2010). As an example, for the travel time and travel cost, the longer the travel time, the smaller the choice probability, and so is the travel cost.

\section{Results and Discussions}

The field surveys were conducted for two months in the main terminal $\mathrm{Km}$ 6 Banjarmasin and Banjarbaru. The questionnaire survey was conducted to 125 respondents with the distribution of questions includes:

- Travel time,

- Travel cost,

- Income,

- Mode choice with SP technique, by combining 10 conditions of changes in time, costs, as well as service factors. The 10 combinations as described in Table 2.

Based on the data returned which are already provided with answers, there are only 102 respondents that can be used or that the choice samples that can be analyzed are amounted to1020 choices. In terms of the number of choices obtained, it should at least not less than 1000 data observations to meet the significance of the data (Horowitz et al., 1986). The travel time of mikrolet used is between 45 and 60 minutes with the cost ranging from IDR 7,000 to IDR 9,000 while for the bus, the travel time is used, and alternative bus transport is planned between 45 and 75 minutes with the costs ranging from IDR 4,000 to IDR 9,000. Factors referred to here is; (1) in the forms of comfort (clean, friendly, and comfortable) such as the employees' friendliness in giving service, the cleanliness of the vehicle, vehicles with no unpleasant odor, not bouncy and not noisy vehicles while running, and good lighting, (2) scheduled time and information includes arrival punctuality of public transport in destination cities, (3) assurance includes security and safety of luggage and passengers guarantee, and problem solving guarantee experienced by passengers, and (4) ease of using the transports (nearby and complete supporting facilities) such as the availability of waiting rooms and comfortable rests, clean toilets, and clear information display. 
Table 2

Combination of Options Based on Changes in Travel Time, Travel Cost, and Service Factors

\begin{tabular}{|c|c|c|c|c|c|}
\hline \multirow[b]{2}{*}{ Condition } & \multicolumn{2}{|l|}{ Mikrolet } & \multicolumn{2}{|l|}{ Bus } & \multirow{2}{*}{$\begin{array}{l}\text { Service } \\
\text { factors }\end{array}$} \\
\hline & $\begin{array}{l}\text { Travel time } \\
\text { (minute) }\end{array}$ & $\begin{array}{l}\text { Travel cost } \\
\left(\mathrm{IDR}^{*}\right)\end{array}$ & $\begin{array}{l}\text { Travel time } \\
\text { (minute) }\end{array}$ & $\begin{array}{l}\text { Travel cost } \\
\text { (IDR) }\end{array}$ & \\
\hline 1 & 55 & 7,000 & 60 & 5,000 & no \\
\hline 2 & 55 & 8,000 & 70 & 4,000 & no \\
\hline 3 & 60 & 7,000 & 60 & 4,000 & no \\
\hline 4 & 60 & 9,000 & 60 & 4,000 & no \\
\hline 5 & 45 & 7,000 & 60 & 7,000 & yes \\
\hline 6 & 45 & 7,000 & 75 & 4,000 & yes \\
\hline 7 & 45 & 7,000 & 50 & 9,000 & yes \\
\hline 8 & 45 & 7,000 & 45 & 9,000 & yes \\
\hline 9 & 45 & 7,000 & 60 & 4,000 & yes \\
\hline 10 & 50 & 9,000 & 60 & 7,000 & yes \\
\hline
\end{tabular}

* IDR (Indonesian currency); 1USD 11,611 IDR - July 2014

\subsection{Logit Model Analysis}

The analysis of the parameter of coefficient of estimation used Logit method. The data used for analysis is the data obtained from the field survey results which directly affect the mode choice, namely:

1. Travel time - in minutes,

2. Travel cost - in rupiahs (IDR) according to the mode used,

3. Income - in Rupiahs,

4. Services - for transports prioritizing on services $=1$; others $=0$,

5. Mode choice.

The data analysis was performed by using TSP (Time Series Processor), a general econometrics software package. Models obtained by means of trial \& error for the formula to obtain the best. The requirements to obtain the best formula are:
- Absolute t-value from the result of the calculation $>$ t-table, thus yielding P-value which approaches 0 or $<\alpha(=$ $0.05)$ to illustrate that the attribute reviewed is valid for use.

- $\quad$ sseudo- $\mathrm{R}^{2}$ value $\geq 0.21$ to show a significant relationship with a strong degree of correlation.

- Algebraic sign obtained from the coefficient of estimation on the parameters of travel time and costs is negative (-). It means that as expected, the result of the model calibration is in accordance with logical criteria (rational). Service factors are expected to have a positive value $(+)$.

The analysis was performed with the two approaches, the first is without regard to the service factors on the model formed and the second is with regard to the service. The analysis result of the best model of estimation parameters is shown in Table 3. 
Table 3

Parameter Estimation

\begin{tabular}{|l|l|l|l|l|}
\hline \multirow{2}{*}{ Variable } & Without service factor & \multicolumn{2}{l|}{ By service factor } \\
\cline { 2 - 5 } & Estimate & P-Value & Estimate & P-Value \\
\hline Travel time & -0.04066 & 0.000 & -0.04466 & 0.000 \\
\hline Travel cost & -0.00026 & 0.000 & -0.00030 & 0.000 \\
\hline Constant of Bus & 0.94196 & 0.000 & 0.36295 & 0.014 \\
\hline Service factor & - & - & 0.96255 & 0.000 \\
\hline pseudo-R & 0.20386 & 0.23251 & \\
\hline Total HIT Ratio & 0.73235 & 0.78039 & \\
\hline Total HIT Ratio Bus & 1.00000 & 0.95716 & \\
\hline Total HIT Ratio Mikrolet & 0.00000 & 0.29670 \\
\hline
\end{tabular}

From Table 3, it is shown that all the values of P-Value of each attribute $<0.05$. It means that the attributes partially reviewed show a significant effect on their independent variables. The algebraic sign of the attributes of travel time and travel cost is corresponding (-) because the longer travel time or the greater costs applied, it will reduce the level of choice, and so is the service factor $(+)$ which means that the services provided will increase the choice. Reviewed from the correlation value of ( $\left.\rho s e u d o-\mathrm{R}^{2}\right)$ model in overall, it appears that there is an improvement of model relationship if being included in the model, the attribute of the services (from 0.20386 to 0.23251 ). Besides that, based on the value of Total Hit ratio, the "by service factor" (0.78039) tending to show higher accuracy than the "without service factor" (0.73235) were used for clarification. The accuracy of recall bus in both models was higher and there is improvement in the accuracy of recall mikrolet in "by service factor" model (from 0.0000 to 0.29670 ).
Furthermore, the parameter estimation, the utility equation of each choice can be formed as the following:

$$
\begin{aligned}
& \mathrm{U}_{(\text {bus })}=0.36295-0.04466^{*} \operatorname{tr} 1- \\
& 0.00030^{*} \operatorname{cs} 1+0.96255^{*} \mathrm{ser} \\
& \mathrm{U}_{(\text {mikrolet })}=-0.04466^{*} \operatorname{tr} 2-0.00030^{*} \operatorname{cs} 2
\end{aligned}
$$

Where $t r_{i}=$ travel time; and $c s_{i}=$ travel cost; ser $=$ services

From the utility model above, the probability model of mode choice (binomial logit models) for each mode can be made as the following:

$$
\begin{aligned}
& P_{\text {bus }}=\frac{1}{1+\exp ^{-0.36295+0} 04466^{*}\left(r_{1}-r_{2}\right)+0.00030^{*}\left(\sigma_{1}-\sigma_{2}\right)-0.96255^{*} \mathrm{ser}} \\
& P_{\text {mikrolet }}=1-P_{\text {bus }}
\end{aligned}
$$


Where:

$\begin{array}{lll}\mathrm{P}_{\text {bus }} & = & \text { the probability of bus mode choice } \\ \mathrm{P}_{\text {mikrolet }} & = & \text { the probability of mikrolet mode choice } \\ \left(\operatorname{tr}_{1}-\operatorname{tr}_{2}\right) & = & \text { the difference in travel time between bus and mikrolet (in minutes) } \\ \left(\mathrm{cs}_{1}-\mathrm{cs}_{2}\right) & = & \text { the difference in costs between the bus and mikrolet (IDR) } \\ \text { ser } & = & \text { service factors, } 0=\text { services are not provided; } 1=\text { services are provided }\end{array}$

The illustration of service factors provided is in the forms of comfort (clean, friendly, and comfortable), scheduled time and information, safety/security, and ease of using the transports (nearby and complete supporting facilities).

\subsection{The Effect of Services on Travel Cost Sensitivity}

Based on the policy to increase the use of bus as an alternative transport, therefore, by taking into account the travel time between the bus and mikrolet transports which are the same, the amount of the choice probability for bus that will be obtained is as the following:

The difference in costs between the bus and mikrolet is IDR 1,000 thus in the condition when the services are not provided is:

$P_{b u s}=\frac{1}{1+\exp ^{-0.36295+004466^{*}\left(\boldsymbol{r}_{1}-\boldsymbol{r}_{2}\right)+0.00030^{*}\left(\sigma_{1}-\boldsymbol{s}_{2}\right)-0.96255^{*} \mathrm{ser}}}$

$$
\begin{aligned}
& P_{\text {bus }}=\frac{1}{1+\exp ^{-0.36295+0} 04466^{*}(0)+0.00030^{*}(1000)-0.96255^{*} 0} \\
& =0.516
\end{aligned}
$$

With the same steps, the service factors provided are obtained at:

$$
\begin{aligned}
& P_{\text {bus }}=\frac{1}{1+\exp ^{-0.36295+0} 04466^{*}(0)+0.00030^{*}(1000)-0.96255^{* 1}} \\
& =0.736
\end{aligned}
$$

From the choice probability to bus above, it is found that the effect of provision of services in bus is able to increase the choice tendency of the travelers. In the case above, the effect of the service factor is (0.736-0.516) $=0.22$ or increases the choice probability to bus by $22 \%$. Furthermore, the effect of service factors due to the difference in costs or sensitivity is commonly referred as cost attribute sensitivity, particularly on the choice probability level of bus shown in Table 4 .

Table 4

The Probability of Mode Choice Due to Travel Cost Sensitivity

\begin{tabular}{|l|l|l|l|}
\hline \multirow{2}{*}{$\begin{array}{l}\text { Difference of travel cost } \\
\text { Bus - Mikrolet) }\end{array}$} & \multicolumn{3}{l}{ Probability of Bus } \\
\cline { 2 - 4 } (in IDR) & Without services & By services & Difference \\
\hline 0 & 0.590 & 0.790 & 0.200 \\
\hline 1000 & 0.516 & 0.736 & 0.220 \\
\hline 1200 & 0.501 & 0.724 & 0.223 \\
\hline 2000 & 0.441 & 0.674 & 0.233 \\
\hline 2500 & 0.404 & 0.640 & 0.236 \\
\hline 3000 & 0.369 & 0.605 & 0.236 \\
\hline 3500 & 0.335 & 0.568 & 0.234 \\
\hline 4000 & 0.302 & 0.531 & 0.229 \\
\hline 4400 & 0.277 & 0.501 & 0.224 \\
\hline 5000 & 0.243 & 0.456 & 0.214 \\
\hline 5500 & 0.216 & 0.420 & 0.203 \\
\hline Average $=$ & & & 0.222 \\
\hline
\end{tabular}


From Table 4, it is shown that the tendency of the trip maker who will use bus will decrease in line with the larger increase in costs difference. In the condition where there is no difference between bus and mikrolet costs (fare), the tendency to choose bus is still higher, i.e. 0.59 and it will increase again by 0.79 if the service factors are applied to bus transports. The form of the choice tendency can be described as shown in Fig. 2 .

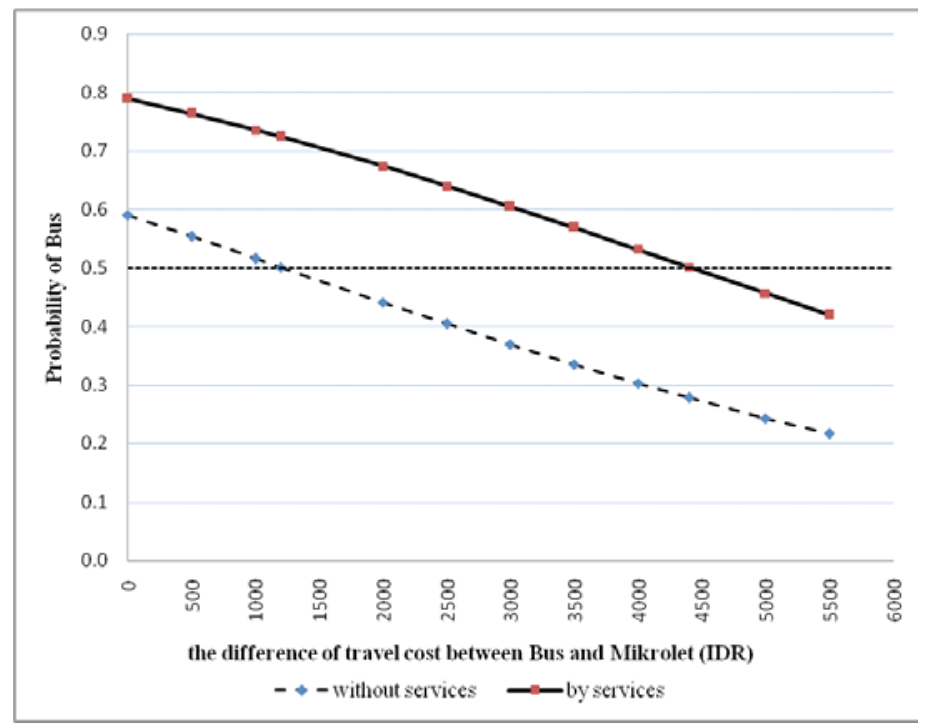

Fig. 2.

Chart of Bus Choice Probability Sensitivity Due to the Difference in Bus and Mikrolet Cost

From Fig. 2, it is shown that the balance condition (the choice between bus and mikrolet is the same / 50:50) occurs if the bus fare is higher by IDR 1,200 than mikrolet without regard to the services. While if the service factors of the bus are considered, the trip maker will still accept the balance condition if the bus fare is increased up IDR 4,400, higher than mikrolet. From the difference in costs that can be applied to bus in both conditions (without and with services), it can be seen that the effect of service factors on the trip makers' willingness to accept the increase in bus fare is IDR 3,200 $(=4,400-1,200)$.

\subsection{The Effect of Services on Travel Time Sensitivity}

With the consideration that the travel time of bus differs from mikrolet due to difference in the size of the same road 
condition. If it is assumed that the fare application between bus and mikrolet is not different, thus the effect of services on the probability of bus choice based on the travel time sensitivity is obtained, as shown in Table 5.

\section{Table 5}

The Probability of Bus Mode Choice Due to Travel Time Sensitivity

\begin{tabular}{|l|l|l|l|}
\hline \multirow{2}{*}{$\begin{array}{l}\text { Difference of travel time } \\
\text { (Bus - Mikrolet) }\end{array}$} & \multicolumn{2}{l}{ Probability of Bus } & \multicolumn{2}{l|}{} \\
\cline { 2 - 4 } (in minute) & Without services & By services & Difference \\
\hline 0 & 0.590 & 0.790 & 0.200 \\
\hline 2 & 0.568 & 0.775 & 0.207 \\
\hline 4 & 0.546 & 0.759 & 0.213 \\
\hline 6 & 0.524 & 0.742 & 0.218 \\
\hline 8 & 0.501 & 0.725 & 0.223 \\
\hline 15 & 0.424 & 0.658 & 0.234 \\
\hline 20 & 0.370 & 0.606 & 0.236 \\
\hline 25 & 0.320 & 0.552 & 0.232 \\
\hline 27 & 0.301 & 0.530 & 0.229 \\
\hline 29 & 0.282 & 0.508 & 0.225 \\
\hline 30 & 0.274 & 0.496 & 0.223 \\
\hline 35 & 0.231 & 0.441 & 0.209 \\
\hline Average $=$ & & & 0.221 \\
\hline
\end{tabular}

From the Table 5, it is shown that people tendency to use bus plan will decrease in line with the greater difference in the travel time if being compared to mikrolet. The form of the choice tendency can be described as shown in Fig. 3.

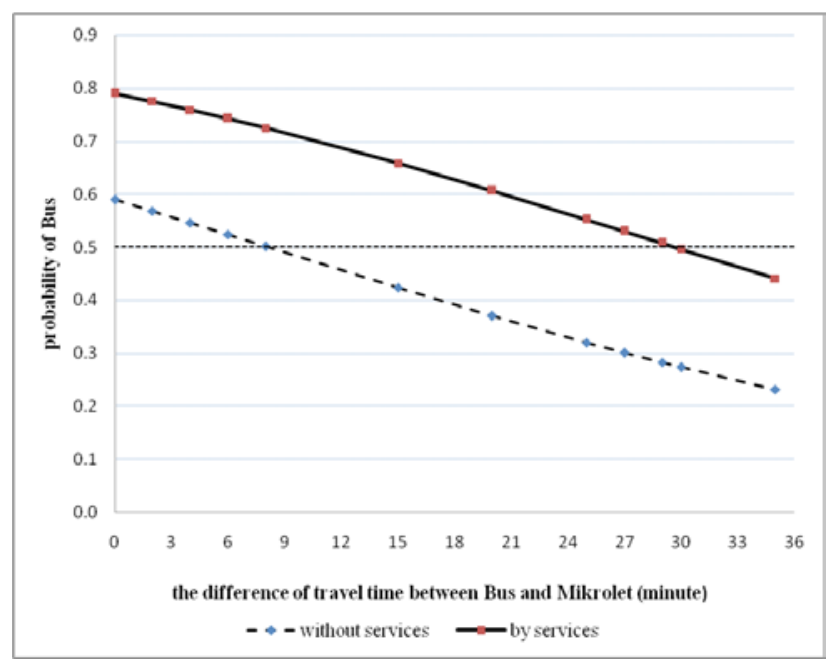

Fig. 3.

Chart of Bus Choice Probability Sensitivity Due to Changes in Travel Time between Bus and Mikrolet 
From Fig. 3, it is shown that the balance condition between bus and mikrolet occurs if the travel time of bus is longer by 8 minutes than mikrolet without regard to the services. From the difference in travel time that can be applied to bus in both conditions (without and with services), it can be seen that the effect of service factors on the trip makers' willingness to accept the bus travel time is 22 minutes $(=30-8)$.

\section{Conclusion}

In the case of the working majority movement of a homogenous society, the service factors become the important attributes that should be considered in the modeling of the mode choice. It is evident from the improvement of the goodness of fit model formed. The Correlation of the model ( $\rho s e u d o-\mathrm{R}^{2}$ ) increases significantly if the service factors are included in the model, i.e. from 0.20386 to 0.23251 , and the hit ratio becomes more accurately. The service factor mentioned is passengers' comfort while using public transports (the perception of cleanliness, friendliness, and comfort), scheduled departure time (punctuality) in accordance with the information provided, the guarantee of safety and security as well as ease in using the transports, both from the availability of the transports and the nearby and complete supporting facilities.

Reviewing the competition of mode choice by trip makers, it is found that the condition of the applied travel time and travel cost to both modes is the same, the probability of bus choice is still high by 0.59 and increases again by 0.79 if the service factors are applied to bus transports. The competition balance between the two modes; the bus cost is still acceptable if higher by IDR 1,200 than mikrolet in a condition without services and increases to IDR 4,400 in a condition with services. While the bus travel time is still acceptable if 8 minutes longer than mikrolet in a condition without services and increases up to 30 minutes if the bus is slower than mikrolet in a condition with services. The average effect of the services on the increase in the choice probability is $22 \%$.

\section{References}

Ben-Akiva, M.; Lerman, S.R. 1985. Discrete Choice Analysis: Theory and Application to Travel Demand. Cambridge: The MIT Press. $71 \mathrm{p}$.

Clark, W.A.; Hosking, P.L. 1986. Statistical methods for geographers. New York: John Wiley and Sons. 518 p.

dell'Olio, L.; Ibeas, A.; Cecin, P. 2011. The Quality of Service Desired By Public Transport Users, Transport Policy. DOI: http://dx.doi.org/10.1016/j. tranpol.2010.08.005, 18(1): 217-227.

Domencich, T.A.; McFadden, D. 1975. Urban Travel Demand: A Behavioral Analysis. Amsterdam: NorthHolland Publishing Company. 124 p.

Eck, J.R.; Burghouwt, G.; Dijst, M. 2005. Lifestyles, Spatial Configurations and Quality of Life in Daily Travel: an Explorative Simulation Study, Journal of Transport Geography. DOI: http://dx.doi.org/10.1016/j. jtrangeo.2004.04.013, 13(2): 123-134.

Grdzelishvili, I.; Sathre, R. 2011. Understanding the urban travel attitudes and behavior of Tbilisi residents, Transport Policy. DOI: http://dx.doi.org/10.1016/j. tranpol.2010.05.006, 18(1): 38-45.

Guilford, J.P. 1956. Fundamental Statistics in Psychology and Education (3rd ed.). New York: McGraw Hill. 145 p. 
Hensher, D.A.; Rose, J.M.; Greene, W.H. 2005. Applied Choice Analysis: A Primer. New York: Cambridge University Press. 63, 337 p.

Hoetker, G. 2007. The use of logit and probit models in strategic management research: critical issues, Strategic Management Journal. DOI: http://dx.doi.org/10.1002/ smj.582, 28(4): 331-343.

Horowitz, J.L.; Koppelman, F.S; Lerman, S.R. 1986. A SelfInstructing Course In Disaggregate Mode Choice Modelling. Washington D.C.: U.S. Department of Transportation. $121 \mathrm{p}$.

Karno, A.; Radam, I.F.; Akpinar, M.V.; Örnek, M. 2004. Analysis of Intercity Transport Mode Choice from Banjarmasin City; Dissagregate Logit Model, Journal of Faculty of Engineering and ArchitectureÇUKUROVA University. DOI: http://dx.doi.org/10.6084/ m9.figshare.1142108, 19(2): 59-68.

Kroes, E.P.; Sheldom, R.J. 1988. Stated Preference Method: An Introduction, Journal of Transport Economics and Policy, 22(1): 11-25.

Ortúzar,J.D.; Willumsen, L.G. 1994. Modelling Transport (2nd ed.). Chichester, England: John Wiley \& Sons Ltd. $188,208,211$ p.
Paulley, N.; Balcombe, R.; Mackett, R.; Titheridge, H.; Preston, J.M.; Wardman, M.R.; Shires, J.D.; White, P. 2006. The Demand for Public Transport: The effects of Fares, Quality of Service, Income and Car Ownership, Transport Policy. DOI: http://dx.doi.org/10.1016/j. tranpol.2005.12.004, 13(4): 295-306.

Radam, I.F. 2010. Influence of Service Factor in Mode Choice Between River Moda and Land Moda in Banjarmasin, Jurnal Dinamika Teknik Sipil. https://hdl. handle/11617/1657, 10(1): 34-40.

Radam, I.F.; Kartadipura, R.H.; Yuliana, C. 2014. Passengers' Perception of Service Quality of Intercity Public Transport: A Banjarmasin Case Study, IOSR Journal of Mechanical and Civil Engineering. DOI: http:// dx.doi.org/ 10.9790/1684-11651116, 11(6): 11-16.

Rigas, K. 2009. Boat or Airplane? Passengers' Perceptions of Transport Services to Islands. The Example of the Greek Domestic Leisure Market, Journal of Transport Geography. DOI: http://dx.doi.org/10.1016/j. jtrangeo.2008.07.005, 17(5): 396-401.

Sheffi, Y. 1992. Urban Transportation Network: Equilibrium Analysis with Mathematical Programming Method. Englewood Cliffs, NJ: Prentice Hall Inc. 262 p. 